\title{
The positive role of hope on the relationship between loneliness and unhappy conditions in Hungarian young adults: How pathways thinking matters!
}

Edward C. Chang, Olivia D. Chang, Tamás Martos, Viola Sallay, Ingo Zettler, Patrizia Steca, Marco D’Addario, Ilona Boniwell, Alina Pop, Margarita Tarragona, Gavin R. Slemp, Ji-eun Shin, Amaia de la Fuente \& Olga Cardeñoso

To cite this article: Edward C. Chang, Olivia D. Chang, Tamás Martos, Viola Sallay, Ingo Zettler, Patrizia Steca, Marco D'Addario, llona Boniwell, Alina Pop, Margarita Tarragona, Gavin R. Slemp, Ji-eun Shin, Amaia de la Fuente \& Olga Cardeñoso (2018): The positive role of hope on the relationship between loneliness and unhappy conditions in Hungarian young adults: How pathways thinking matters!, The Journal of Positive Psychology

To link to this article: https://doi.org/10.1080/17439760.2018.1545042

Published online: 14 Nov 2018.

Submit your article to this journal $₫$

Џ Article views: 6

View Crossmark data 


\title{
The positive role of hope on the relationship between loneliness and unhappy conditions in Hungarian young adults: How pathways thinking matters!
}

\author{
Edward C. Chang ${ }^{\mathrm{a}}$, Olivia D. Chang ${ }^{\mathrm{a}}$, Tamás Martos ${ }^{\mathrm{b}}$, Viola Sallay ${ }^{\mathrm{b}}$, Ingo Zettler ${ }^{\mathrm{c}}$, Patrizia Steca ${ }^{\mathrm{d}}$, \\ Marco D'Addario ${ }^{d}$, llona Boniwelle, Alina Pop ${ }^{f}$, Margarita Tarragona ${ }^{9}$, Gavin R. Slemp ${ }^{\text {h }}$, Ji-eun Shin', \\ Amaia de la Fuentej and Olga Cardeñoso
}

\begin{abstract}
aDepartment of Psychology, University of Michigan, Ann Arbor, USA; ${ }^{b}$ Department of Personality, Clinical and Health Psychology, University of Szeged, Szeged, Hungary; 'Department of Psychology, University of Copenhagen, Copenhagen, Denmark; ${ }^{\mathrm{d} D e p a r t m e n t}$ of Psychology, University of Milano-Bicocca, Milan, Italy; 'Department of Psychology, Anglia Ruskin University, Cambridge, UK \& Positran, Épône, France; fDepartment of Communication Science and Public Relations, Dimitrie Cantemir Christian University, Bucharest, Romania; ${ }^{9}$ Department of

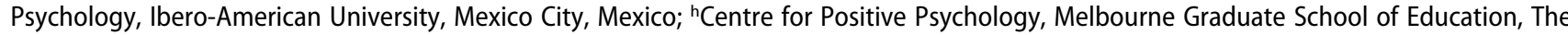
University of Melbourne, Melbourne, Australia; 'College of Liberal Studies, Seoul National University, Seoul, South Korea; 'Department of Developmental and Educational Psychology, University of the Basque Country, Bilbao, Spain
\end{abstract}

\section{ABSTRACT}

In this study, we examined loneliness and hope components as predictors of unhappy conditions (viz., anxious symptoms, depressive symptoms, \& suicidal ideation) in young adults. The sample was comprised of 489 Hungarian college students. Results of conducting hierarchical regression analyses indicated that loneliness and hope pathways (but not hope agency) were important unique predictors of anxious symptoms, depressive symptoms, and suicidal ideation. Moreover, in part, consistent with the notion that hope might buffer the negative effects of loneliness on unhappy conditions, evidence for a significant Loneliness $\times$ Hope Pathways interaction effect in predicting each of the three indices of unhappy conditions was found. In contrast, the Loneliness $\times$ Hope Agency interaction effect was not found to be significant. Some implications of the present findings for the study and treatment of unhappy conditions in adults are discussed.
ARTICLE HISTORY

Received 7 April 2018

Accepted 25 October 2018

\section{KEYWORDS}

Loneliness; hope; unhappiness; adults; college students
Philosophers and psychologists have argued that being lonely represents a fundamental failure to achieve one's necessary sense of belongingness with others in the world and, thus, is a key source of unhappiness for most individuals (e.g., Baumeister \& Leary, 1995; Heidegger, 1962). According to Russell, Peplau, and Cutrona (1980), loneliness is defined by feelings and thoughts of being isolated and disconnected from others. Noteworthy, findings from large scale studies around the world have indicated that many adults experience loneliness (e.g., Victor \& Yang, 2012; Yang \& Victor, 2008). In a large US sample of elderly adults, Theeke (2009) found that $19 \%$ of the sample reported loneliness. Interestingly, the prevalence rates have varied somewhat across different countries. For example, Yang and Victor (2011) found that the prevalence of loneliness was $13.8 \%$ in young adults from Denmark, but was $19.6 \%$ in young adults from Hungary. Despite these variations, what is clear from these findings is that loneliness throughout adulthood represents a universal dimension of being human. Unfortunately, loneliness, as an individual differences variable, has been found in research studies to be a critical risk factor involved in a wide range of maladaptive outcomes associated with experiences of unhappiness.

\section{Loneliness and unhappy conditions in adults}

As urged by Wong (2011), positive psychologists should not only be interested in the study of positive emotional experiences and conditions, namely, happiness, but also the study of negative emotional experiences and conditions, namely, unhappiness. In that regard, studies on loneliness over the past three decades have indicated that it is a robust correlate and predictor of a wide range of unhappy conditions in adults (for reviews, see Hawkley \& Cacioppo, 2010; Heinrich \& Gullone, 2006). Findings from a number of studies have pointed to a reliable association between loneliness and anxiety (e.g., Chang, 2013, 2017; Zawadzki, Graham, \& Gerin, 2013). For example, in a study of young adults, Muyan et al. (2016) found that loneliness was associated with greater anxious symptoms. Similarly, loneliness has been linked to depression (e.g., Cacioppo, Hughes, Waite, 
Hawkley, \& Thisted, 2006; Chang, 2013, 2017). For example, in a prospective study of adults, Cacioppo, Hawkley, and Thisted (2010) found that initial loneliness predicted greater depressive symptoms five years later. Finally, loneliness has also been implicated in perhaps the most extreme symptom of unhappiness (Camus, 1955), namely, suicidal risk (e.g., Chang et al., 2015; Chang, Sanna, Hirsch, \& Jeglic, 2010). For example, in a study of young adults, Muyan and Chang (2015) found that loneliness was associated with greater frequency of suicidal ideation. Yet, beyond studies identifying a positive association between loneliness and unhappy conditions, it would be useful to identify factors that might be associated with weakening the negative effects of loneliness on unhappy conditions. In that regard, there is some emerging evidence to consider hope as a buffer of the relationship between loneliness and unhappy conditions in young adults (Muyan et al., 2016).

\section{Can hope weaken the negative effects of loneliness on unhappy conditions in young adults?: Examining the positive power of agentic and pathways thinking}

Hope has long been considered a defining character of being human (Camus, 1955). Although various psychological models of hope have been presented over the past two decades (see Lopez, Snyder, \& Pedrotti, 2003, for a review), one of the most compelling and comprehensive models has been that provided by Snyder (Snyder, 1994, 2002; Snyder et al., 1991). According to Snyder (1994), all individuals are believed to be guided by efforts to reach and obtain goals through hope. As a universal process involving conscious efforts to obtain a goal, dispositional hope is expected to extend a range of psychological benefits to all individuals (Lopez, 2013; Snyder, 1994; Snyder et al., 1991). In that regard, findings from numerous studies have provided general support for Snyder's (1994) contention that hope represents an adaptive process in adult populations (e.g., Snyder, 1994, 2002; Snyder et al., 1991). Indeed, findings from some studies have provided support for the role of hope as a buffer of the association between maladaptive processes and unhappy conditions in adults (e.g., Hollingsworth, Wingate, Tucker, O'Keefe, \& Cole, 2016; Madan \& Pakenham, 2014). Interestingly, in the only published study, to date, focusing on loneliness and hope as predictors of unhappy conditions in young adults, Muyan et al. (2016) found that hope not only added to the prediction of depressive symptoms (but not anxious symptoms), but also found evidence for a Loneliness $x$ Hope interaction effect in predicting anxious symptoms (but not depressive symptoms).
Unfortunately, these findings do not clarify the extent to which they are due to one or both components of hope.

According to Snyder et al. (1991), hope reflects a cognitive set composed of two relatively distinct ways of thinking about a goal as measured by their Hope Scale. Agentic thinking involves thoughts related to one's successful determination or resolve about reaching goals, whereas pathways thinking involves thoughts about one's effective ability to pursue different means to obtaining goals. Within Snyder et al.'s (1991) hope theory, it is important to consider both types of cognitions as they relate to behavior and outcome. Accordingly, an important tenet of Snyder's (1994) model is that the perception of goal attainment will be, in general, positively associated with greater levels of both agentic and pathways thinking, which in turn will result in each of the hope components being associated with psychological adjustment (e.g., greater life satisfaction). Indeed, findings from a number of studies examining Snyder et al.'s (1991) measure of hope have consistently provided support for a two-dimensional model (e.g., Babyak, Snyder, \& Yoshinobu, 1993; Gana, Daigre, \& Ledrich, 2013; Gomez et al., 2015; Kato \& Snyder, 2005; Martos, Lakatos, \& Tóth-Vajna, 2014; Roesch \& Vaughn, 2006; Sun, Ng, \& Wang, 2012). Given this context, to avoid theoretical and empirical confusion (e.g., loss of information) often associated with measuring a multidimensional construct with a single composite score (Carver, 1989), a more useful test of the role of hope as a buffer of the negative effects of loneliness on unhappy conditions would be to examine the two components of hope, namely, agentic and pathways thinking, separately. Thus, unlike findings provided in Muyan et al.'s (2016) study based on using a composite hope score, a major theoretical and empirical improvement that can be obtained from examining the distinct roles of hope agency and pathways as potential buffers of the association between loneliness and unhappy conditions is the ability to now clarify if one or both components of hope are involved. In turn, such clarification might not only help refine hope theory, but might also help point to the usefulness of focused intervention strategies (e.g., working with individuals to bolster their sense of hope agency, hope pathways, or both) when working with lonely individuals struggling with unhappiness. Finally, given that much of the research on loneliness and hope have been done with WEIRD adult populations (Henrich, Heine, \& Norenzayan, 2010), it would be useful to examine these processes in adults from less WEIRD countries. 


\section{Purpose of the present study}

Given these concerns, we conducted the present study in a sample of Hungarian college students to: 1) examine the relations between loneliness, hope components (viz., hope agency \& pathways), and unhappy conditions (viz., anxious symptoms, depressive symptoms, \& suicidal ideation); 2) determine if, beyond the main effects of loneliness and hope components, there is a significant Loneliness $\times$ Hope interaction effect involving both hope components in predicting unhappy conditions.

Given the contention that loneliness represents a critical failure to achieve needed connectedness with others (Baumeister \& Leary, 1995), we expected to find loneliness to be positively associated with unhappy conditions (e.g., depressive symptoms; Cacioppo et al., 2006; Chang, 2017; Muyan \& Chang, 2015; Zawadzki et al., 2013). Moreover, consistent with past research (e.g., Muyan et al., 2016) and the notion that hope represents a positive psychological construct (Snyder, 1994, 2002), we expected hope components to be negatively related to both loneliness and unhappy conditions. Moreover, to test the general contention that hope represents an important source of personal resilience (Snyder, 1994; Snyder et al., 1991; see also, Hollingsworth et al., 2016; Madan \& Pakenham, 2014; Muyan et al., 2016), and expanding on Muyan et al.'s (2016) initial finding of a significant Loneliness $\times$ Hope interaction effect indicating that the positive association between loneliness and anxious symptoms was found to be weaker for those with high composite hope, compared to low composite hope, we expected to find evidence consistent with the notion that both hope agency and pathways would operate as a buffer of the positive association between loneliness and unhappy conditions. That is, we expected to find evidence of interaction effects involving both Loneliness $\times$ Hope Agency and Loneliness $\times$ Hope Pathways in predicting anxious symptoms, depressive symptoms, and suicidal ideation.

Accordingly, we sought to expand on Muyan et al.'s (2016) study in three important ways. First, we examined the extent to which each component of hope would uniquely predict unhappy conditions in young adults. Second, beyond anxious symptoms and depressive symptoms, we widened the study of unhappy conditions to include suicidal ideation. As studies have found, there exists a strong overlap between negative mood and risk for suicide in adults (Hawton, Comabella, Haw, \& Saunders, 2013). And, third, we tested for the cultural importance of loneliness and hope as predictors of unhappy conditions in young adults from Hungary (cf. young adults from the US; Muyan et al., 2016), a country where mood disorders and suicidal risk have been at historically high levels compared to those in the US and other European countries (Laszlo, Hulman, Csicsman, Bari, \& Nyari, 2015; World Health Organization, 2014). That said, given growing concerns about the narrow band of the world being studied in psychological research (Henrich et al., 2010), it is worth noting that the people of Hungary represent a less WEIRD population (e.g., higher rates of depression, greater levels of poverty, \& historical changes in political regimes; Laszlo et al., 2015) than those typically found in the US and in most Western European countries. Indeed, in contrast to the hundreds of studies examining hope and loneliness based on WEIRD adults (e.g., adults from the US, English-speaking adults, etc.), an examination of the importance of loneliness and hope for understanding unhappy conditions in Hungarian adults has yet to be tested.

\section{Methods}

\section{Participants}

This study consisted of 489 Hungarian college students (250 females \& 239 males) from a large public university in Budapest, Hungary. Participants were solicited from upper-level psychology courses and received extra course credit upon completion of the survey. Ages ranged from 18 to 32 years, with a mean age of 21.67 years $(S D=2.15)$.

\section{Measures}

\section{Loneliness}

To assess for loneliness, we used the revised UCLA Loneliness Scale (R-UCLA; Russell et al., 1980). The scale consists of 20 items that assess for thoughts and feelings of loneliness (e.g., 'I feel isolated from others'). Respondents are asked to rate the statements on the frequency to which they experience these feelings using a 4-point Likert-type scale, ranging from 1 (never) to 4 (often). An adapted Hungarian version of the R-UCLA was used in the present study (Csóka, Szabó, Sáfrány, Rochlitz, \& Bódizs, 2007). In the present sample, internal reliability for the R-UCLA was .92. Higher scores on the R-UCLA indicate greater levels of loneliness.

\section{Hope agency and pathways}

Hope components were assessed by the Hope Scale (HS; Snyder et al., 1991). The HS is a 12-item measure of dispositional hope. Four items assess for hope agency (HS-Agency; e.g., 'I meet the goals that I set for myself') and four items assess for hope pathways (HS-Pathways; e.g., 'I can think of many ways to get out of a jam'). The remaining four items are filler items. 
Respondents are asked to indicate how accurately each item describes them using an 8-point Likert-type scale, ranging from 1 (definitely false) to 8 (definitely true). Evidence for the construct validity of the HS has been reported in past studies. For example, Snyder et al. (1991) found that HS scores were positively related to measures of personal control and self-esteem, but negatively related to hopelessness and depressive symptoms. An adapted Hungarian version of the HS was used in the present study (Martos et al., 2014). In the present sample, internal reliability for the HSAgency and HS-Pathways were .86 and .88 , respectively. In general, higher scores on the HS subscales indicate greater hope agency and pathways.

\section{Unhappy conditions}

To assess for unhappy conditions, we assessed for anxious symptoms, depressive symptoms, and suicidal ideation. For anxious symptoms, we used the Beck Anxiety Inventory (BAl; Beck, Epstein, Brown, \& Steer, 1988). The BAl is a 21-item self-report measure consisting of common symptoms of anxiety (e.g., 'Fear of the worst happening'). Respondents are asked to rate the extent to which they had experienced each symptom over the past week using a 4-point scale ranging from 0 (not at all) to 3 (severely). An adapted Hungarian version of the BAl was used in the present study (Perczel Forintos, Kiss, \& Ajtay, 2007b). In the present sample, internal reliability for the BAI was .90 . Higher scores on the BAl indicate greater anxious symptoms.

For depressive symptoms, we used the Beck Depression Inventory (BDI; Beck, Ward, Mendelson, Mock, \& Erbaugh, 1961). The BDI is a commonly used 21 -item measure that assesses for depressive symptomatology (e.g., 'I am so sad or unhappy that I can't stand it'). Respondents are asked to rate the extent to which they have experienced specific depressive symptoms in the past week, across a 4-point Likert-type scale (for example, ' $0=I$ do not feel sad' to ' $3=$ I am so sad or unhappy that I can't stand it'). An adapted Hungarian version of the BDI was used in the present study (Perczel Forintos, Kiss, \& Ajtay, 2007a). In the present sample, internal reliability for the BDI was .92. Higher scores on the $\mathrm{BDI}$ indicate greater depressive symptoms.

For suicidal ideation, we used the Frequency of Suicidal Ideation Inventory (Chang \& Chang, 2016). The FSII is a 5-item scale that assesses for the frequency of suicidal ideation over the past 12 months (e.g., 'Over the past 12 months, how often have you thought about killing yourself?'). Respondents are asked to indicate how frequently they have entertained suicidal thoughts over the past year using a 5-point Likert-type scale, ranging from 1 (never) to 5 (almost every day). An adapted Hungarian version of the FSIl was used in the present study (Chang, Chang, et al., 2017). In the present sample, internal reliability for the FSII was .91. Higher scores on the FSII indicate greater frequency of suicidal ideation.

\section{Procedure}

Approval for this study was obtained from the Institutional Review Board at the university where the study was conducted prior to data collection. All participants signed consent forms and were informed that all test data would be kept strictly confidential.

\section{Results}

Pearson correlations, means, and standard deviations for all study measures are presented in Table 1 . As expected, loneliness was positively correlated with all three indices of unhappy conditions ( $r s=.45$ to .67 , $p s<.001$ ). Similarly, both hope components were negatively associated with unhappy conditions ( $r s=-.26$ to -.46 , $p s<.001)$. Finally, loneliness was negatively associated with both hope agency $(r=-.51, p<.001)$ and hope pathways $(r=-.42, p<.001)$.

\section{Examining loneliness and hope components as predictors of unhappy conditions in young adults}

To examine loneliness and hope components as predictors of unhappy conditions, we conducted a hierarchical regression analysis for each of the three outcomes. To identify unique main effects, loneliness and hope components were entered as a predictor set in Step 1. Next, to determine if hope components might buffer the association found between loneliness and unhappy conditions, we entered the Loneliness $\times$ Hope Agency and Loneliness $\times$ Hope Pathways interaction effects as a set in Step 2. As a general guide, we used Cohen's (1977) convention for small $\left(f^{2}=.02\right)$, medium $\left(f^{2}=.15\right)$, and

Table 1. Pearson correlations between loneliness, hope, and unhappy conditions in adults.

\begin{tabular}{lcccccc}
\hline Measures & 1 & 2 & 3 & 4 & 5 & 6 \\
\hline 1. Loneliness & - & & & & & \\
2. Hope Agency & $-.51^{* * *}$ & - & & & & \\
3. Hope & $-.42^{* * *}$ & $.69^{* * *}$ & - & & & \\
$\quad$ Pathways & & & & & & \\
4. Anxious & $.45^{* * *}$ & $-.26^{* * *}$ & $-.33^{* * *}$ & - & & \\
$\quad$ Symptoms & & & & & & \\
5. Depressive & $.67^{* * *}$ & $-.46^{* * *}$ & $-.44^{* * *}$ & $.70^{* * *}$ & - & \\
$\quad$ Symptoms & & & & & & \\
6. Suicidal & $.57^{* * *}$ & $-.38^{* * *}$ & $-.37^{* * *}$ & $.54^{* * *}$ & $.66^{* * *}$ & - \\
Ideation & & & & & & \\
$M$ & 35.39 & 22.79 & 23.33 & 11.36 & 8.76 & 7.27 \\
$\quad S D$ & 11.46 & 4.74 & 4.57 & 8.94 & 9.01 & 3.68 \\
\hline
\end{tabular}

Note. $N=489$.

${ }^{* * *} p<.001$. 
large effects $\left(f^{2}=.35\right)$ to determine whether any of the predictors accounted for a small, medium, or large amount of the variance in unhappy conditions.

Results for predicting anxious symptoms, depressive symptoms, and suicidal ideation are presented in Table 2. As the table shows, the loneliness and hope components set accounted for a large $\left(f^{2}=.31\right) 24 \%$ of the variance in anxious symptoms. Within the predictor set, only loneliness $(\beta=.41, p<.001)$ and hope pathways $(\beta=-.24$, $p<.001)$ were significant predictors. When the interaction effects were entered, it was found to account for a small $\left(f^{2}=.01\right)$, but significant $1 \%$ of additional unique variance in anxious symptoms. Within the predictor set, only the Loneliness $\times$ Hope Pathways interaction effect $(\beta=-.63$, $p<.01)$ was a significant predictor. The total model was found to account for a large $\left(f^{2}=.33\right) 25 \%$ of the variance in anxious symptoms, $F(5,483)=31.81, p<.001$.

In predicting depressive symptoms, the loneliness and hope components set accounted for a large $\left(f^{2}=.92\right) 48 \%$ of the variance in depressive symptoms. Within the predictor set, only loneliness $(\beta=.57, p<.001)$ and hope pathways ( $\beta=-.16, p<.001$ ) were significant predictors. When the interaction effects were entered, it was found to account for a small $\left(f^{2}=.04\right)$, but significant $4 \%$ of additional unique variance in depressive symptoms. Within the predictor set, only the Loneliness $\times$ Hope Pathways interaction effect $(\beta=-.90, p<.001)$ was a significant predictor. The total model was found to account for

Table 2. Results of hierarchical regression analyses showing amount of variance in unhappy conditions accounted for by loneliness and hope.

\begin{tabular}{|c|c|c|c|c|c|}
\hline Outcome & $\beta$ & $R^{2}$ & $\Delta R^{2}$ & $F$ & $p$ \\
\hline \multicolumn{6}{|l|}{ Anxious Symptoms } \\
\hline Step 1: Main Effects & & .24 & & 49.55 & $<.001$ \\
\hline Loneliness & $.41^{* * *}$ & & & & \\
\hline Hope Agency & .09 & & & & \\
\hline Hope Pathways & $-.24^{* * *}$ & & & & \\
\hline Step 3: Interaction Effects & & .25 & .01 & 4.21 & $<.05$ \\
\hline Loneliness $\times$ Hope Agency & .26 & & & & \\
\hline Loneliness $\times$ Hope Pathways & $-.63^{* *}$ & & & & \\
\hline \multicolumn{6}{|c|}{ Depressive Symptoms } \\
\hline Step 1: Main Effects & & .48 & & 148.49 & $<.001$ \\
\hline Loneliness & $.57^{* * *}$ & & & & \\
\hline Hope Agency & -.05 & & & & \\
\hline Hope Pathways & $-.16^{* * *}$ & & & & \\
\hline Step 3: Interaction Effects & & .51 & .04 & 17.51 & $<.001$ \\
\hline Loneliness $\times$ Hope Agency & .18 & & & & \\
\hline Loneliness $\times$ Hope Pathways & $-.90^{* * *}$ & & & & \\
\hline \multicolumn{6}{|l|}{ Suicidal Ideation } \\
\hline Step 1: Main Effects & & .34 & & 83.59 & $<.001$ \\
\hline Loneliness & $.49 * * *$ & & & & \\
\hline Hope Agency & -.03 & & & & \\
\hline Hope Pathways & $-.14^{* *}$ & & & & \\
\hline Step 3: Interaction Effects & & .37 & .03 & 12.74 & $<.001$ \\
\hline Loneliness $\times$ Hope Agency & .05 & & & & \\
\hline Loneliness $\times$ Hope Pathways & $-.79 * * *$ & & & & \\
\hline
\end{tabular}

a large $\left(f^{2}=1.04\right) 51 \%$ of the variance in depressive symptoms, $F(5,483)=102.17, p<.001$.

Finally, in predicting suicidal ideation, the loneliness and hope components set accounted for a large $\left(f^{2}=.52\right)$ $34 \%$ of the variance in suicidal ideation. Within the predictor set, only loneliness $(\beta=.49, p<.001)$ and hope pathways $(\beta=-.14, p<.01)$ were significant predictors. When the interaction effects were entered, it was found to account for a small $\left(f^{2}=.03\right)$, but significant $3 \%$ of additional unique variance in suicidal ideation. Within the predictor set, only the Loneliness $\times$ Hope Pathways interaction effect $(\beta=-.79, p<.001)$ was a significant predictor. The total model was found to account for a large $\left(f^{2}=.59\right) 37 \%$ of the variance in suicidal ideation, $F(5$, 483) $=57.68, p<.001$.

To visually inspect the manner in which loneliness and hope pathways interacted with each other in predicting unhappy conditions, we plotted the regression of anxious symptoms, depressive symptoms, and suicidal ideation on loneliness at low and high levels $( \pm 1$ SD below \& above the mean [23.93 \& 46.85], respectively) of low and high hope pathways $( \pm 1$ SD below $\&$ above the mean [18.76 \& 27.90], respectively), based on our initial regression results for the three indices of unhappy conditions (see Figures 1-3). Thus, there were four conditions, namely, low loneliness and low hope pathways $(n=6)$, low loneliness and high hope pathways $(n=24)$, high loneliness and low hope pathways $(n=28)$, and high loneliness and high hope pathways $(n=11)$. As the figures show, the results of plotting these interactions offer consistent support for the notion that hope pathways buffers the positive association between loneliness and unhappy conditions. Specifically, among lonely students, having high hope pathways was associated with lower anxious symptoms, lower depressive symptoms, and lower suicidal ideation, compared to those with low hope pathways.

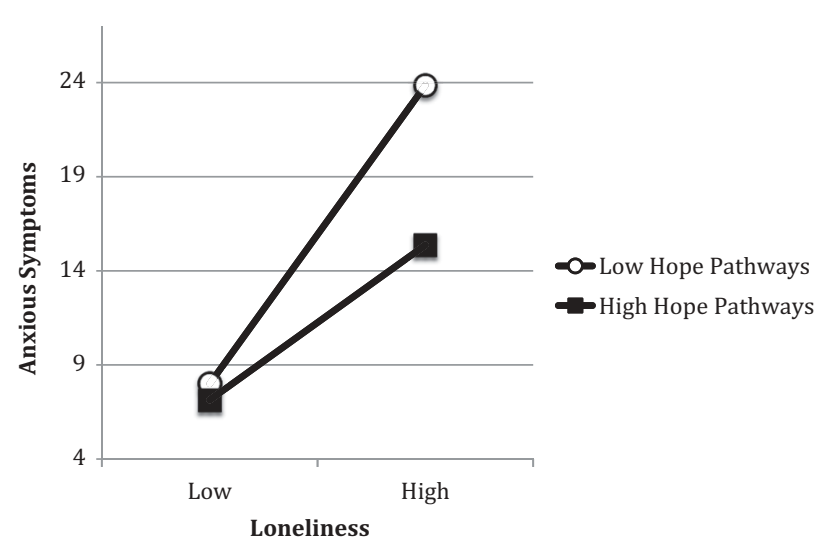

Figure 1. Anxious symptoms at low vs. high hope pathways for non-lonely and lonely students. 


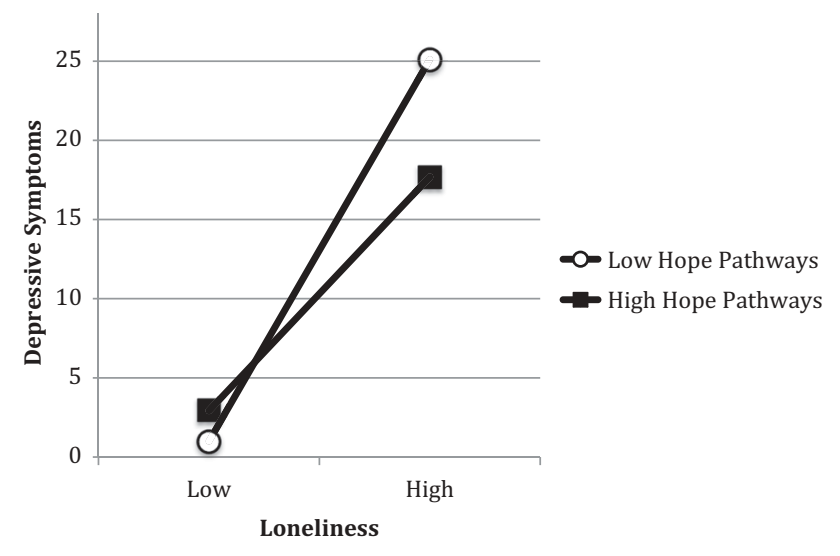

Figure 2. Depressive symptoms at low vs. high hope pathways for non-lonely and lonely students.

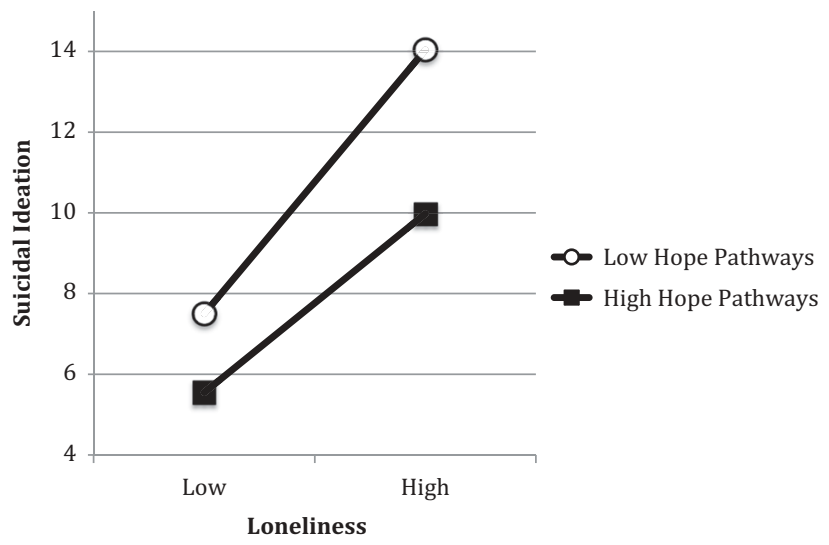

Figure 3. Suicidal ideation at low vs. high hope pathways for non-lonely and lonely students.

\section{Is agentic thinking unimportant in predicting unhappy conditions?: A look at structure coefficients}

Although the present results are based on using common general linear model procedures for testing the relative importance of predictors, these findings might underestimate the importance of the relationship between hope agency and unhappy conditions. Specifically, if both hope agency and pathways explain for the same variance in unhappy conditions, then a variety of factors might result in one hope component emerging as significant, while the other does not (Thompson \& Borrello, 1985). Additionally, the inclusion of loneliness might also result in one hope component getting 'credit' for predicting unhappy conditions, due to the overlap between the larger variance accounted for by loneliness over the smaller variance accounted for by the hope component not getting credit. One solution for better understanding how a variable is related to an outcome, independent of the relationship among the predictors, is to calculate structure coefficients (Courville \& Thompson, 2001). Accordingly, we conducted a set of ad-hoc analyses in which the structure coefficient $\left(r_{\mathrm{s}}\right)$ for each predictor was computed using syntax for SPSS (Stellefson, Hanik, Chaney, \& Chaney, 2008). These additional analyses were conducted to complement, rather than discount, our $\beta$ weight findings from our earlier regression analyses (Thompson \& Borrello, 1985). For anxious symptoms, the structure coefficients were $r_{\text {sAgency }}=-.54, r_{\text {sPathways }}=-.69$, and $r_{\text {sLoneliness }}=.93$ (all $\left.r_{\mathrm{s}}<.001\right)$. For depressive symptoms, the structure coefficients were $r_{\text {sAgency }}=-.66, r_{\text {spathways }}=$ -.64 , and $r_{\text {sLoneliness }}=.97$ (all $r_{\mathrm{s}}<.001$ ). Lastly, for suicidal ideation, the structure coefficients were $r_{\text {sAgency }}=-.65$, $r_{\text {spathways }}=-.63$, and $r_{\text {sLoneliness }}=.97$ (all $r_{\mathrm{s}}<.001$ ). Apart from the robust importance of loneliness, these results indicate that both hope agency and pathways are useful variables for understanding unhappy conditions in young adults. Although these additional results do not negate the importance of our earlier regression findings in which hope pathways, but not hope agency, consistently emerged as a significant unique predictor of unhappy conditions, our findings collectively indicate that hope agency, compared to hope pathways, might be more susceptible to having it's variance associated with unhappy conditions be accounted for by loneliness (Stellefson et al., 2008).

\section{Discussion}

One goal of the present study was to examine the relations between loneliness, hope components, and unhappy conditions in young adults. Consistent with past research findings pointing to loneliness as a critical concomitant of unhappy conditions in adults (e.g., Cacioppo et al., 2006; Chang, 2017; Chang et al., 2015), we found loneliness to be positively associated with all three indices of unhappy conditions, namely, anxious symptoms, depressive symptoms, and suicidal ideation. Accordingly, these findings indicate that young adults who feel disconnected or isolated from others are not only more likely to be anxious and dysphoric, but they are also more likely to entertain frequent thoughts involving lethal self-harm. Alternatively, consistent with the notion that components of hope, namely, hope agency and pathways, represent protective factors against maladjustment (Snyder, 1994, 2002), both hope agency and pathways were found to be negatively associated with all three indices of unhappy conditions assessed in the present study. That is, young adults who thought they had the ability to achieve their goals and thought they knew how to achieve those goals were not only less likely to 
be anxious and dysphoric, but also less likely to harbor thoughts involving lethal self-harm. Overall, these findings underscore a central point, namely, the importance of considering multiple factors, both negative and positive, that may be associated with unhappy conditions in adults (Chang, Downey, Hirsch, \& Lin, 2016).

Expanding on some earlier findings pointing to the role of both loneliness and (composite) hope in anxious symptoms and depressive symptoms (Muyan et al., 2016), another important goal of the present study was to determine the unique contributions of loneliness and hope components in predicting unhappy conditions in young adults. Consistent with expectations, we found that both loneliness and hope were unique predictors of all three indices of unhappy conditions in young adults. As noted earlier, the pattern of the findings for loneliness is consistent with past research findings pointing to loneliness as a robust concomitant and predictor of unhappy conditions in adults (e.g., Hawkley \& Cacioppo, 2010; Heinrich \& Gullone, 2006). Noteworthy, however, by examining the two components of hope (cf. Muyan et al., 2016), we were able to specifically identify the role of hope pathways, but not hope agency, in predicting unhappy conditions in young adults.

The pattern of the findings involving hope pathways, but not hope agency, as a unique predictor of unhappy conditions in adults is somewhat inconsistent with Snyder et al.'s (1991) general contention that both components of hope help facilitate goal achievement and adjustment. That said, studies that have examined for the differential involvement of hope components in psychological adjustment in young adults have indeed sometimes highlighted their equal importance (e.g., Chang et al., 2013). However, more often than not, other studies have indicated the stronger involvement of hope agency, over hope pathways (e.g., Chang, 2003; Chang, Jilani, et al., 2017; Muyan \& Chang, in press). For example, in one recent study, Chang et al. (2016) found that hope agency, but not hope pathways, was uniquely associated with less depressive symptoms in a large sample of young adults from the US. In contrast, in a study of African American young adults, Davidson, Wingate, Slish, and Rasmussen (2010) found that hope pathways, but not hope agency, predicted suicidal ideation. Given that most of the findings showing the greater role of hope agency, compared to hope pathways, have been based on studies of European American adults, our findings raise the possibility that the comparative role of hope agency and pathways in predicting unhappy conditions in adults might in part vary as a function of more complicated cultural or ethnoracial contexts and associated conditions (e.g., experiences of discrimination, low SES, \& lack of social support; Chang et al., 2016). However, in addition to studying hope components within a more inclusive and diverse framework (Chang \& Banks, 2007), it might be useful to recall our structure coefficients findings for hope components and loneliness. Specifically, we were able to show that both hope agency and pathways are important in accounting for unhappy conditions in young adults, but that the inclusion of loneliness had a greater suppressive impact on the role of hope agency, than on the role of hope pathways. Thus, an evaluation of structure coefficients to assess for potential suppressor effects (Courville \& Thompson, 2001), especially when related predictors are included in the prediction model, might also help explain for the relative importance of hope agency and pathways in accounting for psychological adjustment in adults.

Moreover, consistent with the notion that hope components might buffer the association between loneliness and unhappy conditions, we found evidence for a significant Loneliness $\times$ Hope Pathways interaction effect in predicting anxious symptoms, depressive symptoms, and suicidal ideation. For all three interactions, the plots indicated a weaker association between loneliness and unhappy conditions under high, compared to low, hope pathways. In contrast, no evidence for a Loneliness $\times$ Hope Agency interaction effect was found. Thus, in contrast to Muyan et al.'s (2016) general finding that hope (measured as a composite) can buffer the negative effects of loneliness on negative affective conditions, we were not only able to show that hope consistently buffered the effects of loneliness across all anxious symptoms, depressive symptoms, and suicidal ideation, but we were also able to identify support for a more specific view of hope as a buffer, namely, that hope pathways, but not hope agency, represents an important and distinct protective factor in diminishing the potential negative effects of loneliness on unhappy conditions in young adults. Overall, these findings for hope pathways underscore the contention that the inability to consider ways to achieve a goal might represent one important source of unhappiness in adults (Baumeister \& Vohs, 2002).

Accordingly, our findings point to at least two important implications for developing strategies to potentially reduce unhappy conditions in young adults. First, our findings underscore the general importance of working with distressed young adults to reduce their experience of loneliness. For example, when working with an adult experiencing heightened levels of anxiety, dysphoria, or suicidal ideation, it may prove useful for a counselor to focus on a number of specific processes to reduce feelings of loneliness (e.g., increasing 
opportunities for social interaction with others, participating in a social support group, targeting maladaptive social cognitions; Masi, Chen, Hawkley, \& Cacioppo, 2011). In turn, reducing experiences of loneliness might also confer potential benefits by unblocking, or elevating, a sense of agency. Second, our findings also indicate the importance of working with distressed young adults to build and maintain a sense of hope, perhaps, especially in terms of facilitating pathways thinking. One possible way would be to teach young adults how to approach goals using effective problemsolving strategies (D'Zurilla \& Nezu, 2006). For example, it might be useful to help young adults learn how to not only generate a variety of potential solutions to reach a goal, but also how to engage in effective solution implementation and subsequent verification of their solution for reaching their goal. Moreover, one might speculate that given the dynamic and reciprocal nature of the relationship between hope agency and pathways (Snyder, 1994, 2002), engaging distressed young adults in problem-solving training efforts to generate more useful pathways to reaching a goal might in turn help enhance their sense of hope agency (e.g., see their goal as more obtainable) to foster positive change.

\section{Some limitations of the present study}

Despite these important findings pointing to the importance of loneliness and components of hope in predicting unhappy conditions in young adults, it is important to note some limitations. First, given that we focused on the study of young adults, it is not clear if the present model is useful in studying unhappy conditions across different age groups (e.g., adolescents, elderly). Second, rather than engaging in the convention often taken by positive psychologists who have emphasized the study of happy conditions (Wong, 2011), we focused on the study of unhappy conditions. Thus, what is not clear is if the present prediction model is also useful in predicting happy (hedonic) conditions and outcomes in young adults. Also, because loneliness and hope have been implicated as important predictors of physical adjustment and health in adults (e.g., Curry, Snyder, Cook, Ruby, \& Rehm, 1997; Hawkley \& Cacioppo, 2010), it would be useful to test the explanatory power of our model in predicting important physical conditions and outcomes (e.g., physical symptoms, vitality, \& mobility). Third, given that we studied adults from Hungary, a country that is less WEIRD than the US, it remains unclear if our findings are generalizable to adults from other less WEIRD countries (e.g., Turkey, China, Russia, \& India) or to adults of different ethnoracial backgrounds (e.g., African Americans, Asian Americans, \& multiethnoracials; Chang et al., in press). Indeed, even within Hungarian adults, it would be useful to test the present model in more diverse groups (e.g., older working adults) to determine how context and culture might provide a more nuanced understanding of the roles of loneliness and hope on unhappy conditions in adults. Fourth, given that the present study, like the majority of the studies conducted on loneliness and hope in adults, was based on using self-report measures, it would be useful to consider different methods in future research (e.g., peer reports). Lastly, given the cross-sectional nature of the present findings, it would be important in the future to conduct longitudinal studies to determine if loneliness and hope are prospectively associated with changes in unhappy conditions across time.

\section{Concluding thoughts}

In the present study, we examined the role of loneliness and hope components as predictors of unhappy conditions in young adults. Beyond the role of loneliness as a predictor of unhappy conditions, we also found that hope pathways, but not hope agency, was uniquely predictive of unhappy conditions. Moreover, we found that hope pathways, but not hope agency, also moderated the positive association found between loneliness and unhappy conditions. Overall, findings from the present study not only point to the value of how positive psychological capital (e.g., high vs. low hope pathways) might weaken the harmful effects of loneliness on the experience of unhappy conditions in young adults, but they also underscore the usefulness of evaluating for the function of hope components separately, perhaps especially when conducting studies involving adults from previously understudied cultural backgrounds.

\section{Acknowledgments}

The first author would like to acknowledge Tae Myung-Sook and Chang Suk-Choon for their encouragement and support throughout this project.

\section{Disclosure statement}

No potential conflict of interest was reported by the authors.

\section{References}

Babyak, M. A., Snyder, C. R., \& Yoshinobu, L. (1993). Psychometric properties of the Hope Scale: A confirmatory analysis. Journal of Research in Personality, 27, 154-169.

Baumeister, R. F., \& Vohs, K. D. (2002). The pursuit of meaningfulness in life. In C. R. Snyder \& S. J. Lopez (Eds.), Handbook of 
positive psychology (pp. pp. 608-618). New York: Oxford University Press.

Baumeister, R. F., \& Leary, M. R. (1995). The need to belong: Desire for interpersonal attachments as a fundamental human motivation. Psychological Bulletin, 117, 497-529.

Beck, A. T., Epstein, N., Brown, G., \& Steer, R. A. (1988). An inventory for measuring clinical anxiety: Psychometric properties. Journal of Consulting and Clinical Psychology, 56, 893-897.

Beck, A. T., Ward, C. H., Mendelson, M., Mock, J., \& Erbaugh, J. (1961). An inventory for measuring depression. Archives of General Psychiatry, 4, 561-571.

Cacioppo, J. T., Hawkley, L. C., \& Thisted, R. A. (2010). Perceived social isolation makes me sad: 5-year cross-lagged analyses of loneliness and depressive symptomatology in the Chicago health, again, and social relations study. Psychology and Aging, 25, 453-463.

Cacioppo, J. T., Hughes, M. E., Waite, L. J., Hawkley, L. C., \& Thisted, R. A. (2006). Loneliness as a specific risk factor for depressive symptoms: Cross-sectional and longitudinal analyses. Psychology and Aging, 21, 140-151.

Camus, A. (1955). The myth of Sisyphus and other essays. J. O'Brien, Trans. New York, NY: Knopf. (Original work published in 1942).

Caver, C. S. (1989). How should multifaceted personality constructs be tested?: Issues illustrated by self-monitoring, attributional style, and hardiness. Journal of Personality and Social Psychology, 56, 577-585.

Chang, E. C. (2003). A critical appraisal and extension of hope theory in middle-aged men and women: Is it to distinguish agency and pathways components? Journal of Social and Clinical Psychology, 22, 121-144.

Chang, E. C. (2013). Perfectionism and loneliness as predictors of depressive and anxious symptoms in Asian and European Americans: Accounting for variations in self-construal schemas. Cognitive Therapy and Research, 37, 1179-1188.

Chang, E. C. (2017). Perfectionism and loneliness as predictors of depressive and anxious symptoms in African American adults: Further evidence for a top-down additive model. Cognitive Therapy and Research, 41, 720-729.

Chang, E. C., \& Banks, K. H. (2007). The color and texture of hope: Some preliminary findings and implications for hope and counseling among diverse racial/ethnic groups. Cultural Diversity and Ethnic Minority Psychology, 13, 94-103.

Chang, E. C., \& Chang, O. D. (2016). Development of the Frequency of Suicidal Ideation Inventory: Evidence for the validity and reliability of a brief measure of suicidal ideation frequency in a college student population. Cognitive Therapy and Research, 40, 549-556.

Chang, E. C., Chang, O. D., Lee, J., Lucas, A. G., Li, M., Castro, K. M., ... Jeglic, E. L. (in press). Going beyond ethnoracial discrimination and social support in accounting for psychological adjustment: Evidence for the importance of hope as a positive psychological construct in multiethnoracial adults. The Journal of Positive Psychology.

Chang, E. C., Chang, O. D., Martos, T., Sallay, V., Najarian, A. S.M., \& Lee, J. (2017). Validity of the Frequency of Suicidal Ideation Inventory in Hungarian adults. Death Studies, 41, 236-240.

Chang, E. C., Downey, C. A., Hirsch, J. K., \& Lin, N. J. (2016). Introduction to positive psychology in racial and ethnic groups: A second call to action! In E. C. Chang, C. A. Downey, J. K. Hirsch, \& N. J. Lin (Eds.), Positive psychology in racial and ethnic groups: Theory, research, and practice (pp. 3-12). Washington, DC: American Psychological Association.

Chang, E. C., Jilani, Z., Fowler, E. E., Yu, T., Chia, S. W., Yu, E. A., ... Hirsch, J. K. (2016). The relationship between multidimensional spirituality and depressive symptoms in college students: Examining hope agency and pathways as potential mediators. The Journal of Positive Psychology, 11, 189-198.

Chang, E. C., Jilani, Z., Yu, T., Lin, J., Muyan, M., \& Hirsch, J. K. (2017). Relation between sexual assault and negative affective conditions in female college students: Does loss of hope account for the association? Journal of Interpersonal Violence, 32, 1249-1266.

Chang, E. C., Kahle, E. R., Yu, E. A., Lee, J. Y., Kupfermann, Y., \& Hirsch, J. K. (2013). Relations of religiosity and spirituality with depressive symptoms in primary care adults: Evidence for hope agency and pathway as mediators. The Journal of Positive Psychology, 8, 314-321.

Chang, E. C., Lian, X., Yu, T., Qu, J., Zhang, B., Jia, W., ... Hirsch, J. K. (2015). Loneliness under assault: Understanding the impact of sexual assault on the relation between loneliness and suicidal risk in college students. Personality and Individual Differences, 72, 155-159.

Chang, E. C., Sanna, L. J., Hirsch, J. K., \& Jeglic, E. L. (2010). Loneliness and negative life events as predictors of hopelessness and suicidal behaviors in hispanics: evidence for a diathesis-stress model. Journal Of Clinical Psychology, 66, 1242-1253.

Cohen, J. (1977). Statistical power analysis for the behavioral sciences (Rev. ed.). New York, NY: Academic Press.

Courville, T., \& Thompson, B. (2001). Use of structure coefficients in published multiple regression articles: $\beta$ is not enough. Educational and Psychological Measurement, 61, 229-248.

Csóka, S., Szabó, G., Sáfrány, E., Rochlitz, R., \& Bódizs, R. (2007). Kísérlet a felnőttkori kötődés mérésére-A kapcsolati kérdőív (Relationship Scale Questionnaire) magyar változata. [An attempt to measure adult attachment-The Hungarian version of the Relationship Scale Questionnaire]. Pszichológia, 27, 333-355.

Curry, L. A., Snyder, C. R., Cook, D. L., Ruby, B. C., \& Rehm, M. (1997). Role of hope in academic and sport achievement. Journal of Personality and Social Psychology, 73, 1257-1267.

D'Zurilla, T. J., \& Nezu, A. M. (2006). Problem-solving therapy: A positive approach to clinical intervention (3rd ed. New York: Springer.

Davidson, C. L., Wingate, L. R., Slish, M. L., \& Rasmussen, K. A. (2010). The great black hope: Hope and its relation to suicide risk among African Americans. Suicide and LifeThreatening Behavior, 40, 170-180.

Gana, K., Daigre, S., \& Ledrich, J. (2013). Psychometric properties of the French version of the adult dispositional hope scale. Assessment, 20, 114-118.

Gomez, R., McLaren, S., Sharp, M., Smith, C., Hearn, K., \& Turner, L. (2015). Evaluation of the bifactor structure of the Dispositional Hope Scale. Journal Of Personality Assessment, 97, 191-199.

Hawkley, L. C., \& Cacioppo, J. T. (2010). Loneliness matters: A theoretical and empirical review of consequences and mechanisms. Annals of Behavioral Medicine, 40, 218-227.

Hawton, K., Comabella, C. C. I., Haw, C., \& Saunders, K. (2013). Risk factors for suicide in individuals with depression: 
A systematic review. Journal of Affective Disorders, 147, 17-28.

Heidegger, M. (1962). Being and time. Trans. J. Macquarrie \& E. Robinson. Oxford, UK: Blackwell Publishers Ltd. (Original work published in 1927).

Heinrich, L. M., \& Gullone, E. (2006). The clinical significance of loneliness: A literature review. Clinical Psychology Review, 26, 695-718.

Henrich, J., Heine, S. J., \& Norenzayan, A. (2010). The weirdest people in the world? Behavioral and Brain Sciences, 33, 61-135.

Hollingsworth, D. W., Wingate, L. R., Tucker, R. P., O'Keefe, V. M., \& Colee, A. B. (2016). Hope as a moderator of the relationship between interpersonal predictors of suicide and suicidal thinking in African Americans. Journal of Black Psychology, 42, 175-190.

Kato, T., \& Snyder, C. R. (2005). The relationship between hope and subjective well-being: Reliability and validity of the dispositional Hope Scale, Japanese version. Japanese Journal of Psychology, 76, 227-234.

Laszlo, A. M., Hulman, A., Csicsman, J., Bari, F., \& Nyari, T. A. (2015). The use of regression methods for the investigation of trends in suicide rates in Hungary between 1963 and 2011. Social Psychiatry and Psychiatric Epidemiology, 50, 249-256.

Lopez, S. J., Snyder, C. R., \& Pedrotti, J. T. (2003). Hope: Many definitions, many measures. In S. J. Lopez \& C. R. Snyder (Eds.), Positive psychological assessment: A handbook of models and measures (pp. pp. 91-106). Washington, DC: American Psychological Association.

Lopez, S. J. (2013). Making hope happen: Create the future you want for yourself and others. New York: Atria Books.

Madan, S., \& Pakenham, K. I. (2014). The stress-buffering effects of hope on adjustment to multiple sclerosis. International Journal of Behavioral Medicine, 21, 877-890.

Martos, T., Lakatos, C., \& Tóth-Vajna, R. (2014). A Remény Skála magyar változatának (AHS-H) pszichometriai jellemzõi [Psychometric properties of the Hungarian version of the Adult Hope Scale (AHS-H)]. Mentálhigiéné és Pszichoszomatika, 15, 187-202.

Masi, C. M., Chen, H.-Y., Hawkley, L. C., \& Cacioppo, J. T. (2011). A meta-analysis of interventions to reduce loneliness. Personality and Social Psychology Review, 15, 219-266.

Muyan, M., \& Chang, E. C. (2015). Perfectionism as a predictor of suicidal risk in Turkish college students: Does loneliness contribute to further risk? Cognitive Therapy and Research, 39, 776-784.

Muyan, M., \& Chang, E. C. (in press). Hope as a mediator of the link between intimate partner violence and suicidal risk in Turkish women: Further evidence for the role of hope agency. Journal of Interpersonal Violence.

Muyan, M., Chang, E. C., Jilani, Z., Yu, T., Lin, J., \& Hirsch, J. K. (2016). Loneliness and negative affective conditions in adults: Is there any room for hope in predicting anxiety and depressive symptoms? The Journal of Psychology: Interdiscriplinary and Applied, 150, 333-341.
Perczel Forintos, D., Kiss, Z., \& Ajtay, G. (2007a). Beck Depresszió Kérdőív [Beck Depression Inventory]. In D. Perczel Forintos, Z. Kiss, \& G. Ajtay (Eds.), Kérdőívek, becslöskálák a klinikai pszichológiában (pp. pp. 40-43). Budapest, Hungary: Országos Pszichiátriai és Neurológiai Intézet.

Perczel Forintos, D., Kiss, Z., \& Ajtay, G. (2007b). Beck Szorongás Leltár [Beck Anxiety Inventory]. In D. Perczel Forintos, Z. Kiss, \& G. Ajtay (Eds.), Kérdőivek, becslöskálák a klinikai pszichológiába (pp. pp. 5-6). Budapest, Hungary: Országos Pszichiátriai és Neurológiai Intézet.

Roesch, S. C., \& Vaughn, A. A. (2006). Evidence for the factorial validity of the Dispositional Hope Scale: Cross-ethnic and cross-gender measurement equivalence. European Journal of Psychological Assessment, 22, 78-84.

Russell, D., Peplau, L. A., \& Cutrona, C. E. (1980). The revised UCLA Loneliness Scale: Concurrent and discriminant validity evidence. Journal of Personality and Social Psychology, 39, 472-480.

Snyder, C. R. (1994). The psychology of hope: You can get there from here. New York: Free Press.

Snyder, C. R. (2002). Hope theory: Rainbows in the mind. Psychological Inquiry, 13, 249-275.

Snyder, C. R., Harris, C., Anderson, J. R., Holleran, S. A., Irving, L. M., Sigmon, S. T., ... Harney, P. (1991). The will and the ways: Development and validation of an individual-differences measure of hope. Journal of Personality and Social Psychology, 60, 570-585.

Stellefson, M. L., Hanik, B. W., Chaney, B. H., \& Chaney, J. D. (2008). A tutorial on calculating and interpreting regression coefficients in health behavior research. The Health Educator, 40, 12-20.

Sun, Q., Ng, K.-M., \& Wang, C. (2012). A validation study on a new Chinese version of the Dispositional Hope Scale. Measurement and Evaluation in Counseling and Development, 45, 133-148.

Theeke, L. A. (2009). Predictors of loneliness in US adults over age sixty-five. Archives of Psychiatric Nursing, 23, 387-396.

Thompson, B., \& Borrello, G. M. (1985). The importance of structure coefficients in regression research. Educational and Psychological Measurement, 45, 203-209.

Victor, C. R., \& Yang, K. (2012). The prevalence of loneliness among adults: A case study of the United Kingdom. The Journal of Psychology, 146, 85-104.

Wong, P. T. P. (2011). Positive psychology 2.0: Towards a balanced interactive model of the good life. Canadian Psychology, 52, 69-81.

World Health Organization. (2014). Preventing suicide: A global imperative. Geneva, Switzerland: Author.

Yang, K., \& Victor, C. (2011). Age and loneliness in 25 European nations. Ageing \& Society, 31, 1368-1388.

Yang, K., \& Victor, C. R. (2008). The prevalence of and risk for loneliness among older people in China. Ageing \& Society, 28, 305-327.

Zawadzki, M. J., Graham, J. E., \& Gerin, W. (2013). Rumination and anxiety mediate the effect of loneliness on depressed mood and sleep quality in college students. Health Psychology, 32, 212-222. 